
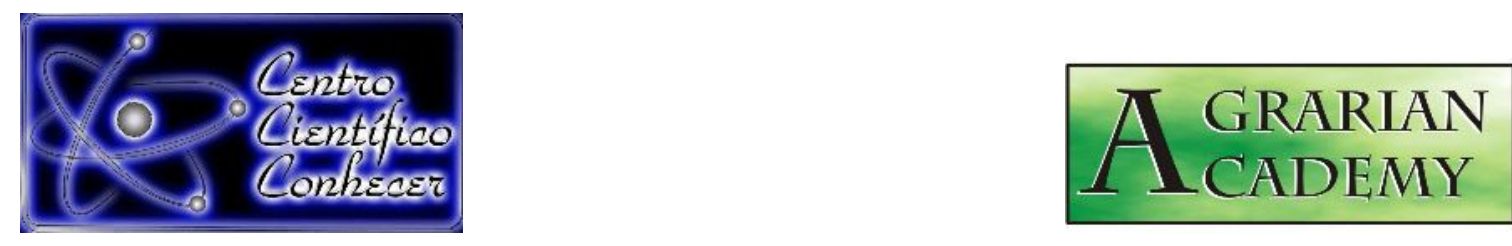

\title{
SANEAMENTO BÁSICO: ESTUDO DE CASO DE PROPRIEDADES RURAIS DO MUNICÍPIO DE SANTA MARGARIDA DO SUL
}

\footnotetext{
Ana Lúcia Alves Rodrigues ${ }^{1}$ Cedinara Arruda Santana Morales ${ }^{2}$,
${ }^{1}$ Gestora Ambiental.Universidade Federal do Pampa, São Gabriel, RS, Brasil.
E-mail: anagestao2013@gmail.com
${ }^{2}$ Engenheira Florestal. Drâa. Engenharia Florestal. Especialista em Educação
Ambiental e Sustentabilidade. São Gabriel, RS, Brasil.
E-mail: cedinaramorales@gmail.com
Recebido em: 20/11/2019 - Aprovado em: 15/12/2019 - Publicado em: 30/12/2019
DOI: 10.18677/Agrarian_Academy_2019b10
}

\begin{abstract}
RESUMO
O saneamento básico é um termo muito amplo que consiste em ações que visam preservar ou modificar as condições do meio ambiente com a finalidade de prevenir doenças, promover a saúde e melhorar a qualidade de vida da população, impedindo que fatores nocivos venham ocasionar danos no seu bem-estar físico, mental e social. O objetivo desta pesquisa exploratória foi realizar um estudo inicial visando identificar o perfil dos produtores rurais assistidos por extensionistas no município de Santa Margarida do Sul, RS e caracterizar seus conhecimentos básicos sobre saneamento básico e sua relação com o meio ambiente e a saúde rural. Inicialmente, foi realizado um levantamento bibliográfico sobre saneamento básico. Posteriormente, foi elaborado um roteiro de entrevistas, articulado com o referencial teórico, direcionado aos produtores rurais. Após a coleta e análise dos dados, constatou-se que a maioria dos produtores é do sexo masculino, com ensino médio completo e pequenos produtores. Afirmam saber o que é saneamento básico e dizem se preocupar com o saneamento básico e com a saúde rural. No entanto, para alguns indivíduos ainda falta conhecimento, por isso, salientou-se a importância da implantação de ações extensionistas de saneamento ambiental e saúde rural, direcionados aos produtores rurais.
\end{abstract}

PALAVRA-CHAVE: saúde rural, rede de esgoto, resíduos sólidos.

\section{BASIC SANITATION: CASE STUDY CASE STUDY OF THE SANTA MARGARIDA DO SUL}

\begin{abstract}
The basic sanitation is a very broad term consisting of actions that aim to preserve or modify the conditions of the environment in order to prevent disease, promote health and improve the quality of life of the population, preventing harmful factors from causing damage to their environment. physical, mental and social well-being. The
\end{abstract}


objective of this exploratory research was to conduct an initial study to identify the profile of farmers assisted by extension workers in the municipality of Santa Margarida do Sul, RS and to characterize their basic knowledge about basic sanitation and its relationship with the environment and rural health. Initially, a bibliographic survey on basic sanitation was performed. Subsequently, a script of interviews was elaborated, articulated with the theoretical reference, directed to the rural producers. After data collection and analysis, it was found that most producers are male, with complete high school and small producers. They claim to know what basic sanitation is and say they are concerned about basic sanitation and rural health. However, for some individuals, knowledge is still lacking, so the importance of implementing extension actions for environmental sanitation and rural health, directed at rural producers, was stressed.

KEYWORDS: rural health, sewage system, solid and organic residue

\section{INTRODUÇÃO}

Saneamento Básico é definido como o conjunto de serviços que garantem as condições de higiene da população (SOUSA, 2017). Para Guimarães et al. (2007), se caracteriza como um conjunto de ações sócio - econômicas com o objetivo de alcançar salubridade ambiental, o estado de higidez (estado de saúde normal) em que vive a população urbana e rural, no que se refere a sua capacidade de inibir, prevenir ou impedir a ocorrência de endemias ou epidemias vinculadas ao meio ambiente.

A carência de saneamento pode gerar uma série de doenças no ser humano, desde os problemas mais corriqueiros, como a diarreia e doenças dermatológicas, cólera, leptospirose, disenteria bacteriana ao agravamento de epidemias (Dengue, Chikungunya e Zika), causando inclusive a morte, principalmente em crianças e idosos. As doenças são transmitidas pelo uso ou ingestão de água contaminada e pelo contato da pele com o solo e lixo contaminados (SILVA, 2014). Descarte do resíduo de forma errada é atrativo para os insetos e faz com que a horta e solo sejam contaminados (SENAR, 2015). Cavinatto (1992), explica que evitar a disseminação de doenças veiculadas por detritos na forma de esgotos e lixo é uma das principais funções do saneamento básico. Sua falta é um problema cada vez mais grave no País, porque a maioria dos problemas sanitários que afetam a população mundial estão intrinsecamente relacionados com o meio ambiente (GUIMARÃES et al., 2007).

Hoje mais de dois bilhões de pessoas enfrentam riscos graves à saúde porque serviços básicos de água não estão disponíveis, diz relatório da Organização das Nações Unidas (ONU, 2019). Embora todo ser humano tenha direito a uma vida saudável, produtiva e em harmonia com a natureza (BRASIL, 2006).

Populações dos países pobres são mais vulneráveis, à medida que os serviços básicos de água estão disponíveis apenas em pouco mais da metade de todas as instalações de saúde nos países menos desenvolvidos, de acordo com o estudo da OMS e do UNICEF. O relatório também revela desigualdades dentro de países. Comunidades em áreas rurais têm menos chances de ter instalações decentes de assistência de saúde, em comparação com pessoas que vivem em cidades (ONU, 2019).

Segundo pesquisa feita pela Embrapa (2017), no Brasil, a coleta de esgoto nas áreas urbanas atinge no máximo $55 \%$ das residências, enquanto que na área rural esse percentual está abaixo de 5\%. Conforme dado da Pesquisa Nacional por 
Amostra de domicílios PNAD/2014, 34,5\% dos domicílios nas áreas rurais estão ligados às redes de abastecimentos de água com ou sem canalização interna, nos restantes dos domicílios rurais $(65,5 \%)$ a população capta água de chafarizes e poços protegidos ou não, diretamente de cursos de água, sem nenhum tratamento ou de outras fontes alternativas, geralmente inadequadas para consumo humano (IBGE, 2014).

Neste contexto, é fundamental ressaltar que o poder público invista em saneamento básico, estabelecendo mecanismos financeiros de solidariedade urbano-rural por meio de fundos ou recursos fiscais da União, de estados e dos municípios para que as áreas rurais possam sair do campo das mazelas sociais e econômica. Para isso é preciso promover a conscientização, bem como o acesso a informação sobre a importância do saneamento rural e com isso tornar a desverticalização do saneamento rural uma realidade (CASTANHETTI, 2017).

Sendo assim, o objetivo desta pesquisa exploratória foi caracterizar o perfil dos produtores rurais assistidos por extensionistas no município de Santa Margarida do Sul, RS e caracterizar seus conhecimentos básicos sobre saneamento básico e sua relação com o meio ambiente e a saúde rural.

\section{MATERIAL E METODOS}

Inicialmente foi realizado um levantamento bibliográfico sobre saneamento básico, seus aspectos sanitários, destino dos resíduos sólidos e do lixo. Posteriormente, foi dado início a elaboração do questionário tendo como base esse referencial teórico.

Elaborou-se um questionário semiestruturado para a coleta de dados, contendo 16 questões simples e abrangentes, sendo nove com opções de múltipla escolha e sete questões discursivas, nestas os produtores poderiam explanar as suas opiniões. O intuito das questões discursivas foi permitir que os participantes fornecessem, de forma indireta, dados que levassem a conclusões sobre suas atitudes perante as situações em relação aos temas abordados.

$\mathrm{Na}$ sequencia, foi realizada esta pesquisa exploratória. Segundo Queiroz (1992), a pesquisa pode ser considerada exploratória, pois busca o levantamento de informações que posteriormente auxiliarão na compreensão da situação. Além disso, tem a finalidade de conhecer a problemática de estudo, seu significado e o contexto onde está inserida.

A coleta de dados ocorreu in loco, no período de janeiro a fevereiro de 2018 , sendo que os respondentes foram produtores rurais assistidos por extensionistas do município de Santa Margarida do Sul, RS. Este município está localizado na metade sul do Estado do Rio Grande do Sul, na região da campanha, cujas coordenadas

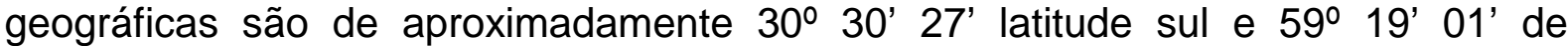
longitude oeste. Tem uma área de 956,1 km², 2.495 habitantes (IBGE, 2015) e pertence à microrregião Campanha Central conforme o IBGE/2010.

O questionário teve como propósito auxiliar na caracterização do perfil do produtor pesquisado e seu conhecimento prévio sobre educação ambiental, conceitos básicos de saúde e saneamento rural.

Os entrevistados foram codificados para garantir o sigilo das informações. Foram utilizadas também fotos e a narrativa dos produtores, captadas na expedição a campo. Matte (2013) afirma que uma forma de complementar a análise é utilizar as narrativas dos discursos, fotos captadas durante a expedição a campo como adjunto às discussões, complementando a análise, assim, confirmando os resultados. 
Após a aplicação do questionário foi realizada a tabulação das informações obtidas. Posteriormente, foi realizada a análise dos dados e, em seguida, a comparação dos mesmos a fim de atender as finalidades desse estudo. Os resultados foram sumarizados através de gráficos, que apresentam uma síntese das respostas obtidas através dos questionários. Para a tabulação das informações e posterior análise dos dados foram utilizados os softwares Microsoft Word e Microsoft Excel.

\section{Caracterização do perfil do produtor rural \\ RESULTADOS E DISCUSSÃO}

Com base nos dados obtidos foi possível fazer primeiramente uma breve caracterização dos produtores. Assim, verificou-se que $60 \%$ dos produtores pesquisados são do sexo masculino, sendo que $30 \%$ são analfabetos, $20 \%$ possuem ensino médio fundamental incompleto, $30 \%$ possuem ensino médio e $20 \%$ nível superior.

Quando questionados sobre o tamanho de suas propriedades, $90 \%$ dos entrevistados têm propriedade com área de até 28 ha, sendo considerados pequenos produtores, pois conforme a classificação do INCRA (2018), a pequena propriedade tem área compreendida entre um e quatro módulos fiscais. Sendo que 28 ha, equivale à um módulo fiscal (INCRA, 2013). A maioria dos produtores produzem para o consumo familiar $(70 \%)$ e somente $30 \%$ produzem para comercialização, no entanto, todos os produtores entrevistados afirmaram não ter empregado na sua propriedade.

A figura 1 apresenta os itens produzidos nas propriedades rurais dos entrevistados. As atividades que se destacam são a pecuária de corte e o plantio de mandioca e milho.

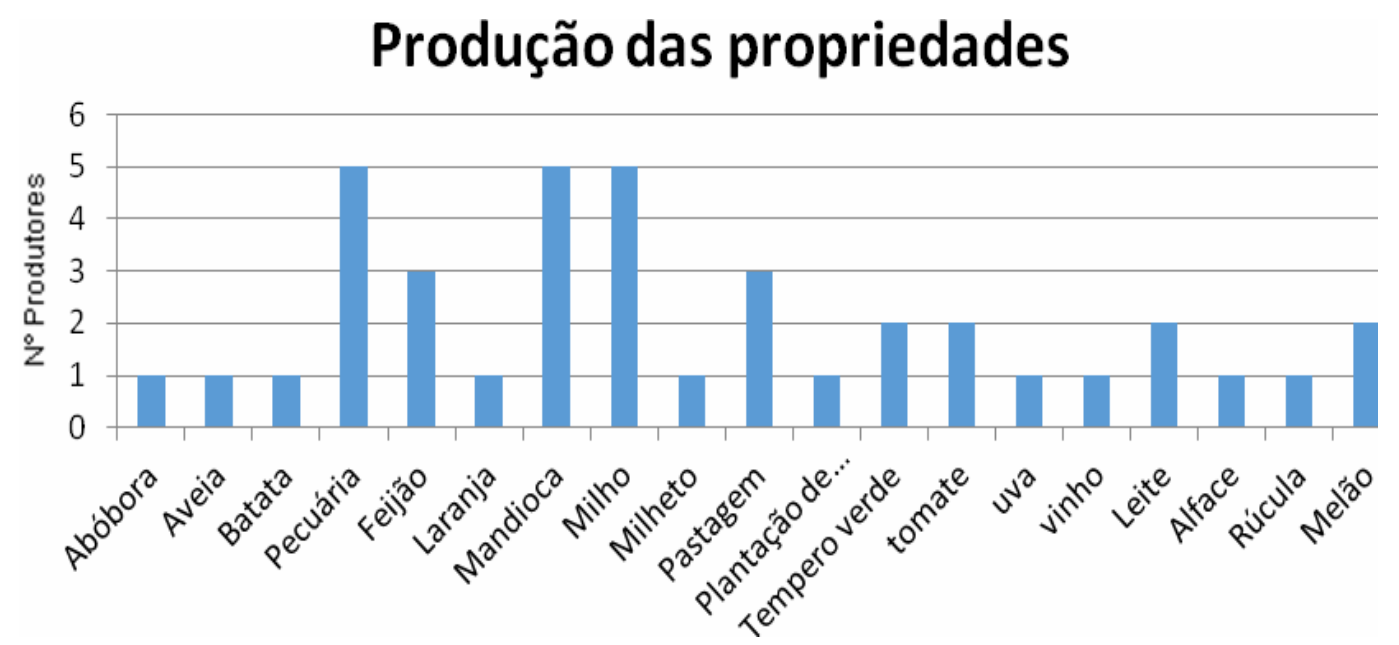

FIGURA 1 - Produtos produzidos nas propriedades rurais dos produtores entrevistados, no município de Santa Margarida do Sul. 


\title{
Saneamento Básico
}

Quando questionados sobre o que é saneamento básico, $90 \%$ dos produtores afirmaram que sabiam o que era e apenas $10 \%$ afirmaram que já ouviram falar mas não sabiam exatamente o que era.

Dentre os entrevistados $90 \%$ afirmaram que saneamento básico é esgotamento sanitário, abastecimento de água potável, limpeza urbana, coleta e destinação de resíduos, drenagem das águas da chuva e controle de enchentes. Somente $10 \%$ consideravam que saneamento básico somente é o esgotamento sanitário.

Segundo Souza (2017), quanto maior for o número de pessoas com uma visão clara e objetiva dos problemas de saneamento ambiental no Brasil, maior será a pressão sobre políticos e dirigentes para a busca de soluções integradas e definitivas que visem sanar a carência de saneamento básico.

Quando questionados sobre os cuidados no preparo dos alimentos para prevenção de doenças (figura 2), a maioria dos produtores afirmaram que lavam bem as mãos e os alimentos para se prevenir de doenças.

\section{Cuidados no Preparo de alimentos}

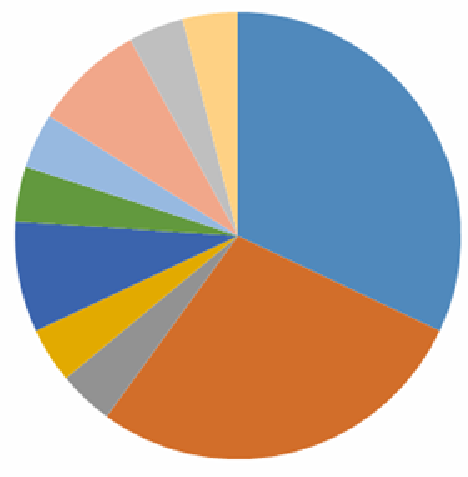

\author{
- Lavar bem as mãos \\ - Lavar bem os alimentos \\ - Cozinhar bem os alimentos \\ Uso de touca \\ - Uso de luvas \\ - Unhas aparadas \\ - Cabelo preso \\ - Limpeza dos utensílios \\ verduras de molho no vinagre
}

FIGURA 2 - Cuidados no preparo dos alimentos para prevenção de doenças realizados pelos produtores rurais de Santa Margarida do Sul, RS.

Quando questionados sobre o que eles faziam para que a produção tenha uma sanidade adequada até chegar à mesa do consumidor (Figura 3 ), 40\% afirmaram não produzir para o consumidor, $10 \%$ afirmaram que não usam agrotóxicos e procuram entregar bem limpos os produtos, $20 \%$ não quiseram responder, $20 \%$ afirmaram que lavam os alimentos e $10 \%$ afirmaram que esterilizam bem os utensílios usados para a entrega dos produtos.

As ações de saneamento devem atingir todas as etapas da cadeia alimentar que vão desde a obtenção do alimento e a produção da matéria-prima até o consumo. Deve-se então assegurar o controle eficiente da qualidade sanitária do alimento em todas essas etapas, dando ênfase especial à educação sanitária dos manipuladores e consumidores de alimentos, no sentido de serem observadas as recomendações sanitárias que garantam a qualidade do alimento (BRASIL, 2006). 


\section{Cuidados com a sanidade dos produtos}

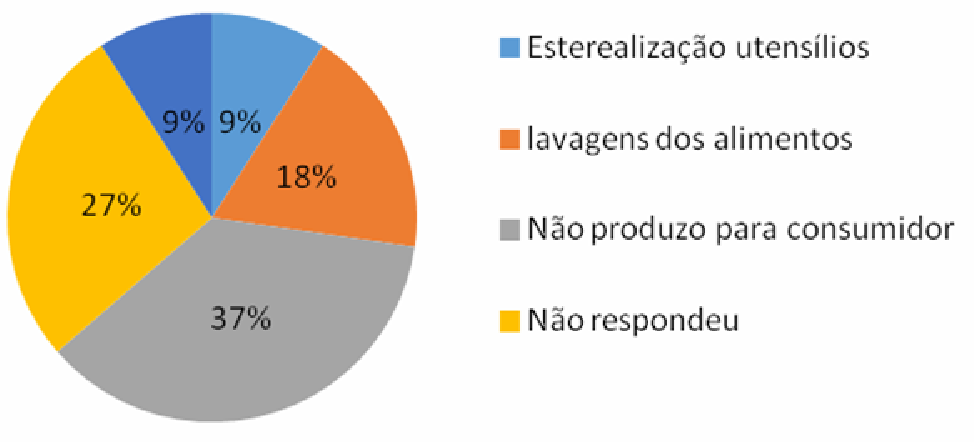

FIGURA 3 - Cuidados com a sanidade dos produtos comercializados realizados pelos produtores rurais de Santa Margarida do Sul, RS.

Quando perguntados sobre quais mananciais havia em sua propriedade, a maioria dos produtores $(90 \%)$ responderam que possuem açude, $60 \%$ poços, $40 \%$ cacimbas e somente $30 \%$ fontes (Figura 4). Entretanto, quando questionados se era feito algum tipo de tratamento na água que eles utilizam para consumo e para o preparo dos alimentos, $50 \%$ dos produtores responderam que usam cloração na água e $50 \%$ não usam cloro, e desses, $10 \%$ usam água filtrada. Dados do Sistema Nacional de Informações sobre Saneamento (SNIS, 2017), referentes a 2015, mostram que cerca de 34 milhões de brasileiros não possuem acesso à água potável (INSTITUTO TRATA BRASIL, 2018).

No entanto, segundo Senar (2015), a água a ser disponibilizada para o consumo da população deve ser adequada em relação aos seus aspectos sanitários, qualitativos e quantitativos. Pois esta é um recurso natural estratégico que serve para diversos objetivos e é importante para a produção de alimentos e para a vida. O mau uso pode trazer consequências, tanto no aspecto qualitativo, quanto no aspecto quantitativo, podendo refletir em aspectos sanitários importantes, como no caso dos agentes causadores de doenças, que a água pode transportar.

\section{Tipos de mananciais existentes nas propriedade rurais}

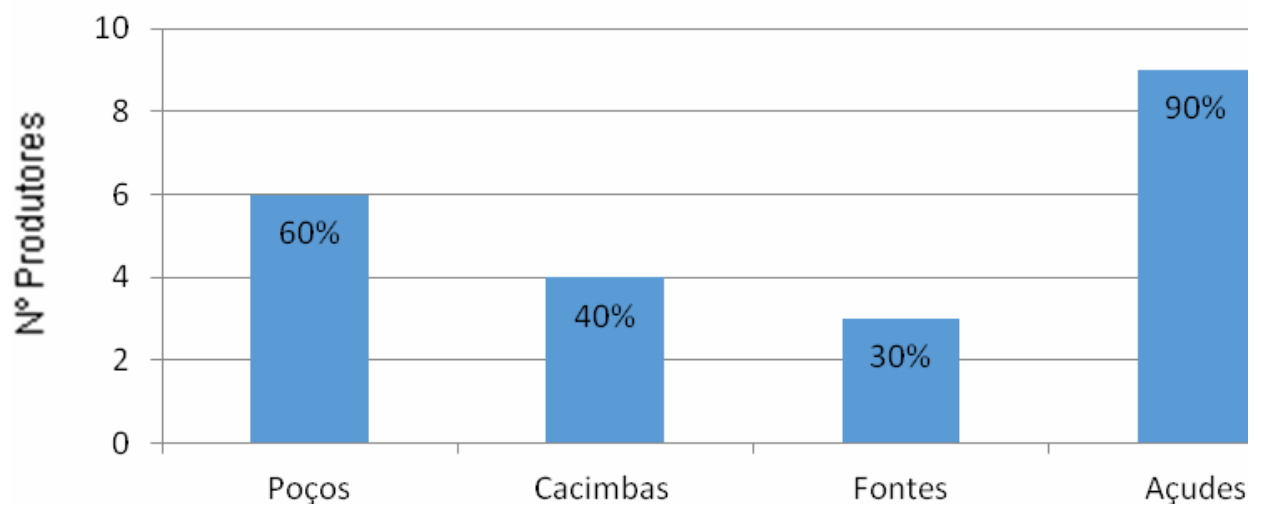

FIGURA 4 - Mananciais existentes nas propriedades rurais de Santa Margarida do Sul, RS. 
Quanto ao destino dos dejetos, quando perguntados, $60 \%$ dos produtores têm fossa séptica, não ligada à rede coletora e sim diretamente no solo a céu aberto, $20 \%$ utilizam a fossa séptica ligada à rede coletora, $10 \%$ mantêm fossa séptica que sai para o poço negro e 10\% não utilizam nada, descartam diretamente a céu aberto. Segundo a Pesquisa Nacional de Amostras de Domicílios (PNDA) em 2015, apenas $5,45 \%$ dos domicílios estão ligados à rede de coleta de esgotos, 4,47\% utilizam a fossa séptica ligada à rede coletora e $28,78 \%$ fossa séptica não ligada à rede coletora como solução para o tratamento dos dejetos. Os demais domicílios $(61,27 \%)$ depositam os dejetos em fossas rudimentares, lançam em cursos d'água ou diretamente no solo a céu aberto.

De acordo com dados do Instituto Trata Brasil, 50,3\% da população tem acesso à coleta de esgoto enquanto mais de 100 milhões de brasileiros ainda não tem acesso a este serviço (INSTITUTO TRATA BRASIL, 2018). Para Leal (2008), o sistema de esgotos sanitários é extremamente importante pois propicia coleta, transporte e afastamento, tratamento, e disposição final das águas residuárias, de uma forma adequada do ponto de vista sanitário e ambiental. Este sistema existe para afastar a possibilidade de contato de dejetos humanos com a população, com as águas de abastecimento, com vetores de doenças e alimentos.

Diversos agentes causadores de doenças podem ser eliminados juntamente com os dejetos humano, o destino inadequado favorece tanto a poluição do solo, da água, e do ar, quanto à contaminação do próprio ser humano. São os patógenos que podem causar diversas doenças, como: Cólera, diarreia, febre Tifoide, hepatites, A e B. Parasitoses humanas, entre outras (SENAR, 2015).

É fundamentalmente importante o destino e tratamento adequados dos dejetos humanos. A falta de tratamento do esgoto sanitário traz várias consequências negativas para a sociedade. A literatura cita a saúde como a principal variável impactada pelas condições sanitárias da população. Nesse contexto, a consequência da falta de tratamento de esgoto, seja rural ou urbano, ocasiona diversas doenças (HELLER, 1997; COSTA; PINHEIRO, 2018).

\section{Destino dos dejetos}

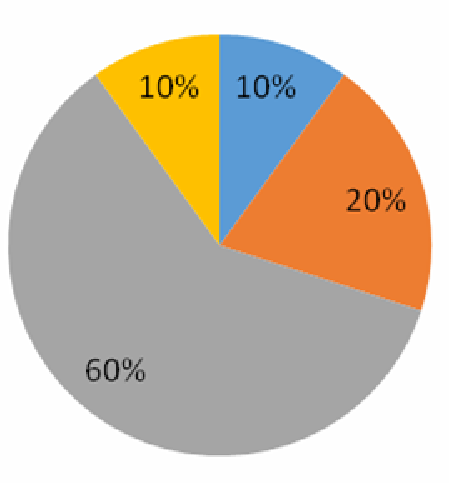

- Fossa séptica ligada ao poço Negro

- Fossa séptica ligada a rede coletora

- Fossa séptica não ligada a rede coletora (diretamente no solo ou a céu aberto)

corre a céu aberto

FIGURA 5 - Destino dos dejetos nas propriedades rurais de Santa Margarida do Sul, RS. 
Quando questionados se os produtores faziam separação dos resíduos sólidos e orgânicos, como por exemplo, caixa de leite, papel, plástico, alumínio e resíduos orgânicos como casca de frutas, cascas de ovos, erva mate (Figura 6), $60 \%$ responderam que fazem a separação, $20 \%$ firmaram que não separam nada $e$ $10 \%$ separam apenas alguns materiais.

Dos $60 \%$ dos entrevistados que fazem à separação dos resíduos sólidos, alguns doam para uma instituição para serem reciclados, deixando-os guardados em locais separados até que tenham uma quantia significativa para transportar até a cidade. Mas em algumas localidades de difícil acesso, alguns produtores não tendo como dar um descarte correto aos resíduos acabam queimando os resíduos sólidos e o lixo.

Em visita a propriedade do produtor 02 verificou-se que esta possui um poço artesiano, mas a água não é tratada e a coleta de lixo não é feita. Contudo segundo o mesmo justifica que por morarem em uma localidade de difícil acesso, o município não tem nenhum interesse em realizar este trabalho, até argumentam que não é problema da prefeitura, mas sim, de cada proprietário que é responsável pelo seu lixo. O mesmo ainda disse que é um crime queimar lixo, mas que ele não tem outra saída. Afirmou ainda que já fez separação do lixo, mas atualmente pela sua condição de saúde ser ruim, não pode sair da sua residência para transportar esse resíduo de bicicleta.

O produtor 04 , soube explicar o que é saneamento básico e apesar de morar em uma localidade de difícil acesso, faz a separação do lixo, as latinhas, papelão, vidro e pet (Figura 6). Ele deposita o lixo seco para fazer o descarte correto, que é transportado até a cidade. Esse material armazenado é doado para uma instituição que se encarrega de ir buscar os resíduos sólidos secos e o resíduo orgânico eles colocam na horta em sua propriedade.

Conforme Ribeiro e Rooke (2010), em virtude dos aspectos sanitários, qualitativos e quantitativos, é muito importante dar atenção especial à questão do destino do lixo, pois sendo realizado adequadamente, vai contribuir para a redução da contaminação ambiental e da propagação de doenças. Assim, à medida que soluções técnicas são adotadas, e quanto mais adequada for a operação dos sistemas de disposição final do lixo, que incorporem modernas tecnologias de tratamento, menores são os impactos para a saúde pública e para o meio ambiente.

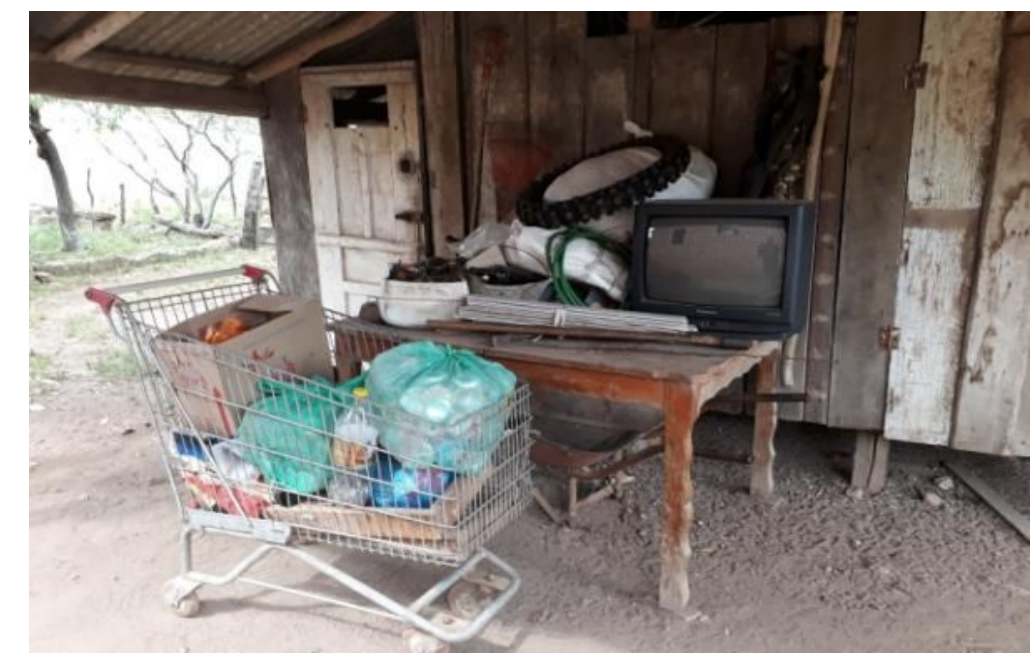

FIGURA 6. Local onde fica guardado o lixo seco. Foto: Ana Lucia Alves (2018). 
Nesta propriedade ainda existe um galinheiro aéreo (Figura 7), as galinhas dormem e os estercos das aves caem para baixo da estrutura. Os produtores aproveitam este resíduo como adubo orgânico, e ao mesmo tempo, esse tipo de galinheiro permite que esteja sempre bem arejado o local, facilitando a ventilação e umidade, e evitando o estresse calórico no galinheiro.

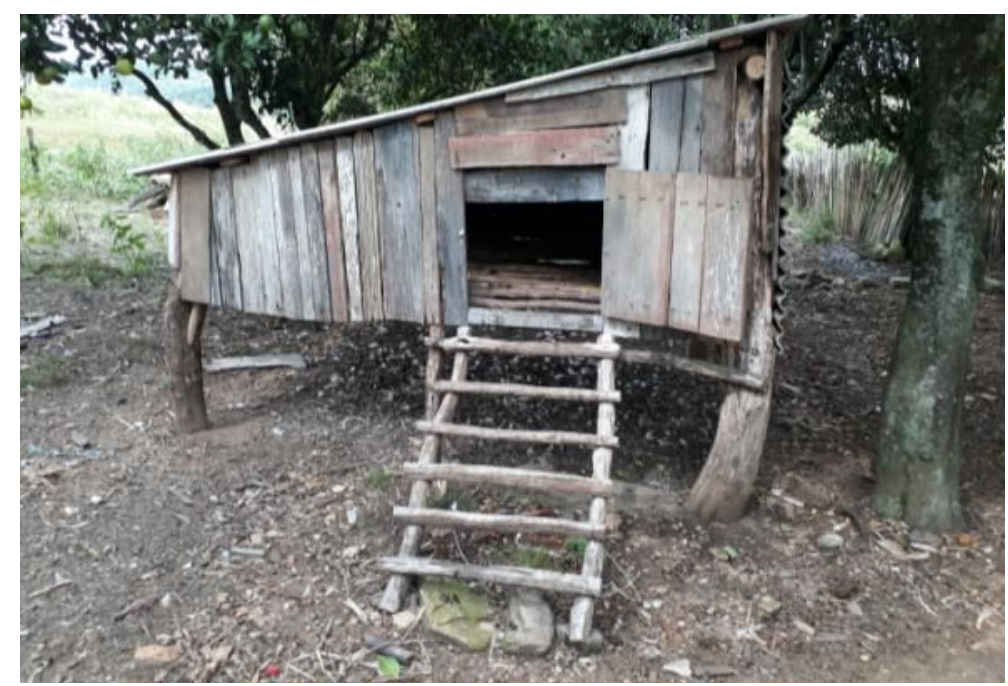

FIGURA 7 - Galinheiro Aéreo.

Foto: Ana Lúcia Alves (2018).

Pode se observar com este estudo que $60 \%$ dos produtores assistidos pelos extensionistas fazem a separação dos resíduos sólidos, 30\% não separam os resíduos e somente 10\% segregam alguns materiais (Figura 8). Estes produtores apresentam todo um acompanhamento, por isso são bem instruídos. Os produtores que não fazem a separação dos resíduos sólidos argumentam que realmente não tem como fazer seu destino correto devido a questões de logística.

Separação dos resíduos sólidos

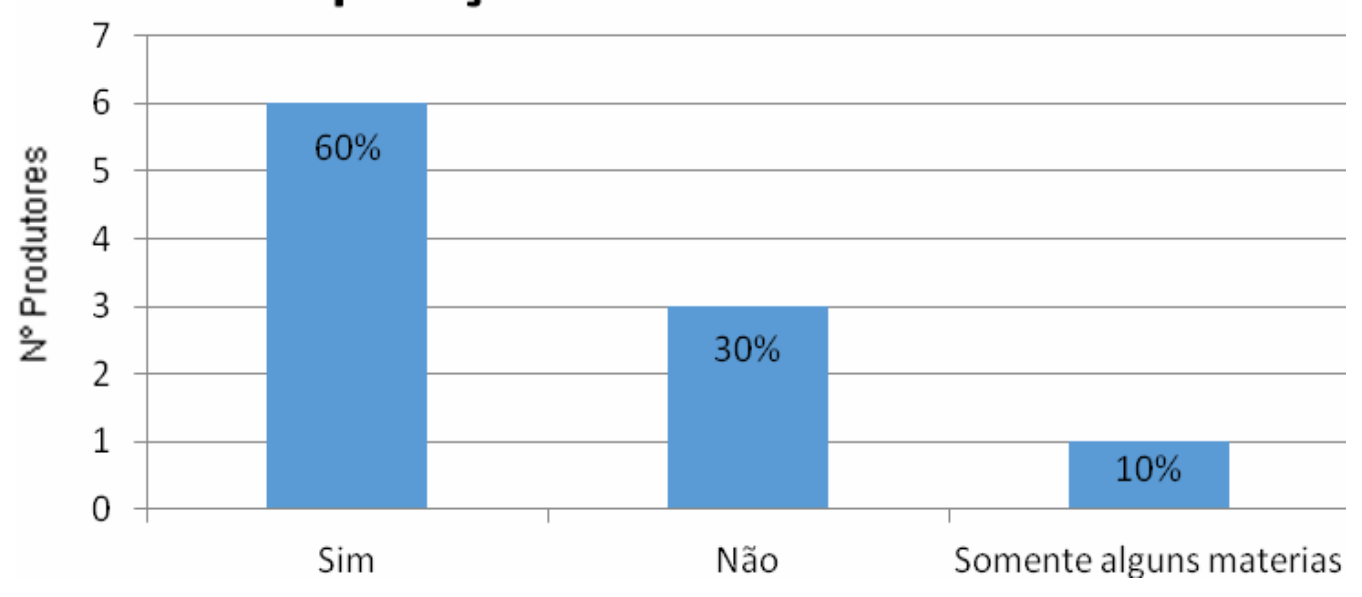

FIGURA 8 - Separação dos resíduos secos recicláveis e orgânicos nas propriedades rurais de Santa Margarida do Sul, RS.

Quanto aos resíduos orgânicos (Figura 9), 70\% dos produtores questionados, reutilizam esses resíduos para alimentar os animais, 30\% usam como adubo e 
desses, $10 \%$ aplicam no minhocário, e 10\% enviam para a cidade de São Gabriel para o descarte correto.

O produtor 05 envia os seus resíduos orgânicos para a cidade porque segundo ele produz muito resíduo orgânico, uma vez que possue uma agroindústria. Este produtor trabalha com a agricultura familiar, silvicultura e hortifruti. Afirmou a ainda ter um cuidado todo especial com a água que é usada na agroindústria e para uso da família. Devido a este cuidado ele construiu uma proteção de fonte com ajuda dos extensionistas da EMATER/ASCAR, e também afirmou que possui um açude na propriedade, no qual a água é tratada e analisada pelos técnicos do município de Santa Maria.

\section{Destinação dos resíduos orgânicos}

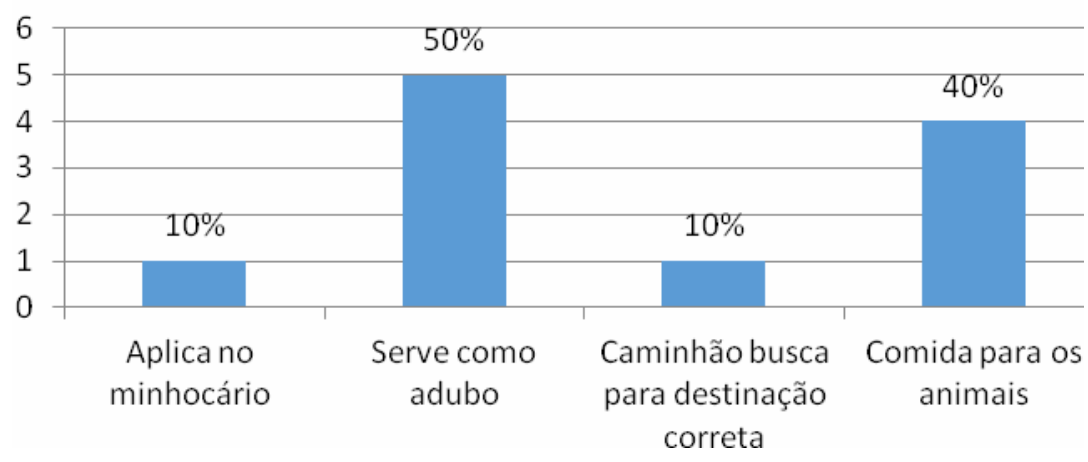

FIGURA 9 - Destinação dos resíduos orgânicos nas propriedades rurais de Santa Margarida do Sul, RS.

Quando questionados se os produtores sabiam que a falta de saneamento pode gerar uma série de doenças no ser humano, causando inclusive a morte, principalmente em crianças e idosos, $100 \%$ dos produtores afirmaram que sim. Em relação às doenças ocasionadas pela falta de saneamento e que são transmitidas pelo uso ou ingestão de água contaminada e pelo contato da pele com o solo e lixo contaminados, $90 \%$ disseram que sim, sabiam e 10\% disseram que não, desconheciam esta informação.

Quando foram abordados sobre formação complementar, foram questionados se já haviam feito algum curso de saúde rural e saneamento básico, e se gostariam de fazer algum curso que possibilitasse maior conhecimento em saúde rural e saneamento básico, $100 \%$ dos produtores entrevistados afirmaram que nunca fizeram nenhum curso de saúde rural e saneamento básico, mas, no entanto, $90 \%$ dos produtores afirmaram que gostariam de fazer este tipo de curso e apenas $10 \%$ disseram que não tinham interesse neste tipo de curso.

\section{CONCLUSÃO}

Analisando os dados concluiu-se que a maioria dos produtores é de pequena propriedade, sexo masculino, com escolaridade variada e produzem que produtos para consumo próprio.

A maioria dos produtores pesquisados afirmam saber o que é saneamento básico e sabem que sua falta pode trazer doenças. Assim, afirmaram lavar bem as mãos e os alimentos para se prevenir de doenças.

Constatou-se que a maioria dos produtores se preocupam com o saneamento básico e saúde rural, porém, para alguns ainda falta conhecimento, por isso, 
verificou-se a importância de ações extensionistas contínuas de saneamento ambiental e saúde rural, direcionados aos produtores, como por exemplo, a realização de um curso de saneamento básico e saúde rural que visem aumentar o conhecimento e esclarecer as dúvidas dos produtores rurais.

\section{REFERÊNCIAS}

BRASIL. Fundação Nacional de Saúde. Manual de saneamento. 3. ed. rev. Brasília: FUNASA, 2006.2 Disponível em: http://www.funasa.gov.br/internet/arquivos/biblioteca/eng/eng_saneam.pdf Acesso em: 21 de dezembro de 2018.

CASTANHETTI, F.J. A falta de sistemas de tratamento de esgoto doméstico em zona rural e suas consequências. Monografia (Especialista Direito Ambiental) Universidade do Sul de Santa Catarina, Içara,SC , 2017.

CAVINATTO, V. M. Saneamento básico: fonte de saúde e bem-estar. São Paulo: Moderna, 1992.

COSTA, R. N. P.; PINHEIRO, E. M. O cenário do saneamento básico no Brasil. Revista Educação Ambiental em Ação, Número 66., 2018. Disponível em: http://www.revistaea.org/artigo.php?idartigo=3523. Acesso em: 21 maio 2019.

EMBRAPA. Sistemas de Tratamento de Esgoto na Zona Rural. http://www.embrapa.gov.br/impresa/noticias/2010/agosto/3a-semana/sistemas-detratamentode-esgoto-na-zona-rural-traz-melhorias-a-saúde-publica-e-ao-meioambiente/. Acessado em $15 / 05 / 2017$

GUIMARÃES, A. J. A.; CARVALHO, D. F. de; SILVA, L. D. B. da. Saneamento básico. Apostila. UFRRJ. 2007 Disponível: http://www.ufrrj.br/institutos/it/deng/leonardo/downloads//Apostila\%20IT\%20179/Cap \%201.pdf. Acesso em: 15 de fevereiro de 2018.

HELLER, L. Saneamento e saúde. Brasília: OPAS.1997.

IBGE, Instituto Brasileiro de Geografia e Estatística - PNAD -Pesquisa Nacional por Amostra de Domicílios: 2014. Rio de Janeiro: IBGE, 2014.

IBGE, Instituto Brasileiro de Geografia e Estatística - PNAD - Pesquisa nacional por amostra de domicílios: síntese de indicadores: 2013. Coordenação de Trabalho e Rendimento. - 2. ed. - Rio de Janeiro : IBGE, 2015.

INCRA. Sistema nacional de cadastro rural - Índices básicos. 2013.

INCRA. Classificação dos imóveis rurais. Disponível em: http://www.incra.gov.br/tamanho-propriedades-rurais Acesso: 10 de fevereiro de 2018. 
INSTITUTO

TRATA

BRASIL.

Disponível

em

http://www.tratabrasil.org.br/saneamento-basico-existencia-de-plano-sera-requisitopara-acesso-a-Recursos-federais-a-partir-de-2018. Acesso: 17/02/2018

LEAL, F. C. T. Sistemas de saneamento ambiental. Faculdade de Engenharia da UFJF. Departamento de Hidráulica e Saneamento. Curso de Especialização em análise Ambiental. 4 ed. Juiz de Fora: 2008.

MATTE, A. Vulnerabilidades, capacitações e meios de vida dos pecuaristas de corte da Campanha Meridional e Serra do Sudeste do Rio Grande do Sul. 2013, 176 f. Dissertação de Mestrado em Desenvolvimento Rural. Universidade Federal do Rio Grande do Sul, Porto Alegre, 2013.

ONU. Falta de água e saneamento deixa milhões de vidas em risco no mundo, diz OMS. Organização das Nações Unidas. 2019 Disponível em: https://nacoesunidas.org/falta-de-agua-e-saneamento-deixa-milhoes-de-vidas-emrisco-no-mundo-diz-oms/ Acesso: 08/05/2019

RIBEIRO, J. W.; ROOKE, J. M. S. Saneamento básico e sua relação com o meio ambiente e a saúde pública. Trabalho de Conclusão de Curso (Especialização em Análise Ambiental) - Faculdade de Engenharia, Universidade Federal de Juiz de Fora, Juiz de Fora, 2010.

QUEIRÓZ, M. I. de P. O pesquisador, o problema da pesquisa, a escolha de técnicas: algumas reflexões. In: Lang, A.B.S.G., org. Reflexões sobre a pesquisa sociológica. São Paulo, Centro de Estudos Rurais e Urbanos, 1992. p. 13-29. (Coleção Textos; 2a série, 3).

SENAR - Curso de doenças transmissíveis e saneamento básico. Módulo 3. Serviço Nacional de Aprendizagem Rural. Brasília, 2015.

SILVA, W. T. L. ABC da Agricultura Familiar - Saneamento básico rural. Brasília, DF :Embrapa , 2014.

SNIS. Sistema Nacional de Informações em Saneamento. Disponível em: http://www.snis.gov.br/. Acesso em: 13 dez. 2016.

SOUSA, F. J. Tópicos de saneamento básico - Águas pluviais e resíduos sólidos. Joinville, SC: Clube de Autores, 2017. 